\title{
Beyond Leadership Theory to Making a Difference in Urban Schools: Engaging Graduate Students in Real World Learning
}

\author{
Frederick M. Hampton ${ }^{1}$ \\ ${ }^{1}$ College of Education, Cleveland State University, Cleveland, USA \\ Correspondence: Frederick M. Hampton, Associate Professor of Eduction, College of Education, Cleveland State \\ University, Cleveland, Ohio, USA.
}

Received: March 29, 2017

Accepted: April 25, 2017

Online Published: May 26, 2017

doi:10.5430/irhe.v2n2p25

URL: https://doi.org/10.5430/irhe.v2n2p25

\begin{abstract}
This paper explores new and important thinking on two university levels. First is an examination of how to more fully engage university graduate students in significant learning experiences, and secondly, how graduate students in school leadership can begin to address real world problems in urban school districts. This paper seeks to move well beyond school leadership theory into practice, and to inspire a re-imagining of our urban school programs, and a reexamination of the issues and problems that prevent highly capable urban youth from reaching their full potential.
\end{abstract}

Keywords: urban students, school leadership, graduate programs, dropout prevention, student achievement, school success

I like to think that the work I've done as a professor of Educational Leadership has made a difference. I enjoy the lively discussions with my graduate students and developing my carefully prepared lessons each week. I look forward to reading the well crafted and scholarly papers that my students write, and the wonderful comments made about me when they evaluate my course. I feel good about the articles that I've published and the research papers I've presented at national education conferences. I like to think that I've made a difference as a professor of educational leadership. But, have I really?

I teach at Cleveland State University, which is located in the center of one of the most distressed public school districts in America. According to the Center for Urban Education (2014), the Cleveland Metropolitan School District faces all the challenges commonly associated with urban schools, including low graduation rates, low student achievement, teen pregnancy, school violence and all the remaining problems related to student poverty. In recent years however, the persistence of these problems has led me to question whether I've made any real difference in my Graduate students, many of whom become administrators in the Cleveland schools.

Some of the typical courses that I teach include: Principles and Practices of School Administration, Instructional Leadership and Pupil Services Administration, and Staff Personnel Administration. In class, the students have routinely studied traditional theories of school leadership, submitted weekly critiques of assigned articles, completed field-based administrative projects, participated in group presentations, and have written extensive research papers. All of those activities and exercises have provided a broad basis for my evaluation of their performance as Graduate students.

In addition to the excellence in scholarship demonstrated by my graduate students, they also exhibit high levels of mastery in all the core and specialized subjects. A vast majority of the students perform extremely well on the Comprehensive Exams and also on the Pearsons National Assessment of School Administrators. Still as these students leave the university, begin careers as school administrators, and assume responsibility for failing schools, I wonder about the importance of all the scholarly papers they've written and the many tests they've passed. For many years I've helped supply the Cleveland schools with administrators, but there is little evidence of fundamental improvement in important public school student outcomes. Without question, the relationship between graduate studies excellence and excellence in solving urban school problems remain unclear.

\section{Focusing on an Urban School Problem}

In the Cleveland schools with so many overwhelming problems, no single issue can actually be considered greater than the next. Moreover, the deep and persistent problems of inner-city schools are such that substantial 
improvement lies beyond the abilities of any single group, including school administrators. Many of the challenges that debilitate an urban student's education are not only related to schools, but are also inextricably linked to parenting, funding, community support, and the local economy (Conchas, 2006). It is not possible to provide all urban students with two caring biological parents, to provide their parents with jobs, job skills, adequate family income, appropriate housing. Nor is getting rid of drugs and gangs an easy matter.

With all of these difficulties, finding effective ways to improve the graduation rate, which hovers around $65 \%$ in Cleveland schools would appear to be a logical starting point (Cleveland Metropolitan School District, 2017). Any reduction in the dropout rate would be significant and indicative that other problems were being addressed. Regardless of all the debilitating personal, family, and community circumstances that interfere with school success, none provide a reason or excuse for a student to dropout. On the contrary, those circumstances should serve as a catalyst for students to strive even more for graduation.

\section{Moving beyond Leadership Theory}

In the fall of 2015, I discussed with one of my classes a school dropout initiative that I'd developed over the past three years, which I refer to as Search and Rescue (Hampton, 2013). In emergency terms, "search and rescue" is defined as the search for and provision of aid to people who are in distress or imminent danger. Urban dropouts are people who are in distress or imminent danger. In this program, I've worked with a Cleveland principal on a goal of returning 10 dropouts to high school, or enrolling them in the district's alternative education program. I believe that helping 10 inner city dropouts to graduate from high school will positively alter the course of their lives, perhaps inspire their younger siblings or friends to remain in school, and improve the city of Cleveland by developing 10 more productive citizens. If the principal and I together could convince 10 dropouts to return to school, what could be the potential combined impact among many teams of educators working to do the same?

Some of my students who teach in Cleveland became intrigued with the idea of also helping to return dropouts to school. Moreover, many of them personally knew students who left school prematurely, and sometimes those students were there own relatives or the children of their friends. Although initially I had not developed this program for graduate student participation, it became clear that some viewed this as an opportunity to engage in a learning experience that could make a real difference in the Cleveland schools. By attempting Search and Rescue, they could demonstrate their leadership ability, gain a more detailed understanding of urban students, help to solve an important urban school problem, and complete a graduate school activity that would be remembered for the rest of their lives. For me, the graduate students' participation would further the Search and Rescue initiative, inform me of additional instructional practices, provide valuable qualitative and quantitative data on dropouts, and establish a stronger relationship between the university and the local school district.

Not every graduate student chose to participate in Search and Rescue. Some felt the experience would be too overwhelming because of the energy already exerted in their own classrooms. Some believed that valuable time might be taken away from their own children at home. Others wanted to participate, but at that particular juncture they were too consumed with the overall workload of graduate school. And, some simply wanted to follow the traditional syllabus and complete the course as quickly as possible. Finally, there were a handful who immediately accepted the challenge, and over the next few weeks we organized the activity and began attempts to rescue high school dropouts.

\section{Reaching Dropouts One at a Time}

For the four students who agreed to participate, the Search and Rescue project would serve in lieu of a standard research paper. However, Search and Rescue would become their field research for the semester. Their grade for the class would not be contingent upon whether or not they ultimately convinced a dropout to return to school, but rather, by their willingness to put forth an honest effort to do so and to maintain an extensive journal of their Search and Rescue activities.

One student pointed out his concern for a teen that was currently enrolled, but skipped school on many more days than she attended. Because of his prior knowledge of this teen, he felt sure that she would dropout as soon as she was 16 years old. He reasoned that if he could intervene before she dropped out, there would be no need to rescue her later. This added a caveat that I had not previously considered, but the sound logic of this position created an additional category of students for our initiative.

Since we were planning and organizing an untested activity as we sought to bring dropouts back into school, we anticipated much learning by trial and error. Also without specific strategies in place, each student was left to his/her own devices and experiences to determine which paths would be most productive. From my own personal 
experiences, I know that convincing a dropout to return to school is a Herculean task which yields a very low probability of success. Still, I believe the strength of this initiative lies in celebrating the success of returning even one student to school, creating an awareness of the possibilities, and establishing teams of educators and parents that work together to rescue dropouts one at a time.

\section{Search and Rescue Guidelines}

To be sure, success in this initiative requires more than just encouraging dropouts to return to school. If the answer to dropping out were that simple, the problem wouldn't exist. Every student who drops out does so for a reason (Doll, Eslami, \& Walters, 2013). The challenge for my graduate students would be to connect with a dropout, understand his/her reasons for leaving, then begin to engage the student in overcoming barriers that prevent their return, if possible.

After establishing contact, each graduate student would be left to use their own "street credibility" and devise their own strategies for reconnecting the dropout to school. However in the interest of safety, uniformity, and collaborations with schools and parents, the graduate students were encouraged to use the same framework for dropout identification, consent protocol, and contact initiation.

\section{Dropout Identification}

- The dropout is still age-eligible to attend public school, but preferably between the ages of $16-19$.

- The dropout may be someone you've taught or worked with previously.

- The dropout may be referred by another teacher.

- The dropout may be one of your relatives.

- The dropout may be a relative of one of your friends.

- The student may be currently enrolled in school, but is at high risk of dropping out.

\section{Dropout Consent Protocol}

- The school principal must be informed of your plans.

- The school counselor must be informed of your plans.

- The parent/guardian must give written consent before interventions take place.

- The dropout must give written consent.

- The dropout has the right to terminate contact with you at any time and for any reason.

\section{Dropout Contact Initiation}

- When receiving written consent from the parent/guardian, seek their support in convincing the dropout to return to school.

- Arrange to have initial contact/conferences in the presence of the parent/guardian, preferably in their home.

- Identify the reason(s) that the dropout left school.

- Ask under what circumstances the dropout would be willing to return to school.

- Discuss the stated circumstances with the dropout and parent/guardian. Make no promises, other than the information will be shared with the principal and school counselor.

- Set a definite time and date for a follow-up meeting with the dropout and parent/guardian if they are available.

- Exchange contact information (email address only) with the dropout and parent/guardian if they have access to the Internet. If there is no Internet access, use your own discretion as to providing your phone number.

\section{The Four Cases}

\subsection{Dan Attempts to Rescue Kory}

Dan did not personally know of a student to attempt a rescue. But, since one of his friends was an attorney, he decided to see if he could find a recommendation there. Dan's friend quickly thought of 19 year old Kory who dropped out of school and had since found himself in criminal trouble. The attorney touched based with Kory and secured permission to pass his phone number along to Dan. Dan followed-up with a call and the two began to plan their first meeting. 
Their first personal encounter occurred at the Justice Center as Kory awaited a pretrial hearing. Kory had dropped out of school as a freshman, was the father of a 9 month old baby, and worked a 40 hour a week job for $\$ 9.00$ an hour. At this meeting, Dan also met Kory's mother, brother, and his girlfriend (the mother of his child). Kory's mother asked Dan to do all that he could to encourage Kory's return to school. Kory told Dan that he wanted to return to school because it was "time for him to grow up."

After several days of waiting for Kory to get a day off work, Dan met Kory at his former high school to review his transcripts. Although there was some hesitance to release the information because of fees that were still due, the two managed to get an unofficial copy that listed Kory's credits. Much to Dan's dismay, the transcripts revealed that Kory had earned no high school credits. At that point, the two decided that pursuit of a GED may be a more appropriate course of action. Dan researched information about where a GED could be obtained, how to download practice exams, and how Kory could register for class.

Two weeks later, Kory called Dan and informed him of his GED enrollment date. Additionally, Kory was scheduled to complete the practice exam later that weekend and would call Dan when the results were returned. Dan and Kory agreed to meet in person again when they could discuss the results and plan the next steps. During the interim, Dan would occasionally make phone calls or send texts to Kory to inquire about his job, the baby, his legal problems, and his continued interest in obtaining his GED.

The day finally arrived when Kory was to begin the GED classes, and the evening schedule would allow him to both work and begin the program. Dan was so happy and excited for Kory that he asked if he could attend on the first evening to speak with the instructor and show his support. Although Kory seemed a little embarrassed by the attention, he understood Dan's excitement and gave permission.

Dan arrived at the GED center 30 minutes before class began to find the correct building, classroom, and to speak with the instructor. Dan introduced himself to the instructor, discussed his reasons for being there, and spoke enthusiastically about Kory. As the evening progressed, Dan continued to look at his watch hoping for Kory's arrival. As the hour passed he made repeated calls to Kory's cell phone, and finally accepted that Kory was not going to show up that evening. The instructor told Dan not to worry and that if Kory showed up for the next session, he would be happy to get him started. Thus began a pattern of non-appearances that would characterize Kory over the coming months.

Early the next morning, Kory called Dan and explained that he was unexpectedly called in to work the previous evening. Although Dan was disappointed that Kory had not made a courtesy phone call, he explained how Kory could still proceed with their plans for the GED. Two days later and without explanation Kory also missed the second session. When he finally managed to attend a session, the instructor informed him that he would now have to wait 2 months until the start of the next GED cohort.

Days went by without Kory returning any phone calls from Dan. In the meantime, Dan contacted Kory's mother and brother to see if they had heard from him. The brother informed Dan that Kory was staying at home and continued to work. When Kory finally returned the call, he informed Dan that several days ago the police had arrested him for drunkenness in a public park. Dan inquired if Kory had a drinking problem and offered to help him seek substance abuse counseling. Kory confirmed that he both drank and "smoked" but he did not consider it a problem and declined the assistance.

One week later, Kory phoned Dan and said again that he was ready to get started on the GED. They made plans to review the GED practice test on a Saturday and afterwards they could do something that Kory enjoyed, e.g., go for hamburgers; watch a football game, etc. Dan also renewed his offer for substance abuse counseling, but once again Kory refused stating that he did not have a problem. Saturday arrived, but as had become Kory's pattern, he did not show up for the review session and no courtesy calls were received from him. Dan continued to follow-up with phone calls to Kory and his mother.

As the semester was coming to a close and Dan had become more discouraged about Kory's efforts, one of Kory's family members called him with an update on the situation. Dan learned that Kory had become quite despondent about his previous legal trouble and was going to enter a plea agreement which would probably keep him out of jail, but would put him on probation. The family member asked that if Kory received probation, would Dan be willing to continue helping him pursue the GED. Dan said the he would continue to help as long as Kory was willing to accept it, and asked if he could attend the court hearing for sentencing. The family member promised to pass the request along to Kory and would let Dan know as soon as possible. Dan's final journal entries discussed still "seeing a light 
at the end of the tunnel", and "hopes that Kory would take advantage of this opportunity for help in returning to school."

\subsection{Luke Attempts to Rescue Latisha}

Latisha is a 16 year old girl who Luke has known for 4 years from $7^{\text {th }}-9^{\text {th }}$ grade, and now she's repeating the $9^{\text {th }}$. According to Luke, she has always been a rebellious and seemingly troubled young girl who has endured a difficult personal and home life for many years. Latisha's mother chose to leave the family when she was three years old, and since then her father has struggled to raise all three children alone. By any reasonable standard, Latisha's father has made many poor decisions in raising his children. To cite but one example, for a brief period, he dated Latisha's best friend, an 18 year old stripper. Latisha's older brother is a high school dropout, and she has stated on previous occasions that she will do likewise. Latisha smokes, drinks, is often truant from school, and since the beginning of this project has informed Luke that she was pregnant.

Luke secured permission from the principal and Latisha's father to attempt the rescue by having daily conversations and problem solving sessions with her. Luke determined that because of Latisha's rebellious nature, he would not immediately reveal his intentions of keeping her in school. Since Latisha had known Luke for four years, she thought his additional interest in her was no more than he would have for any other student. Although frequent truancy continued, on days that Latisha was in school Luke would find time to talk with her about how life was going, including the pregnancy.

Luke sought to use the pregnancy as a motivational tool, in that remaining in school would not only be the best thing for Latisha, but also for the baby. If Latisha completed her education he argued, she would be better able to provide for the child without reliance on the child's father. Additionally, Luke used the opportunity to discuss the importance of prenatal care, in that smoking and drinking could definitely cause harm and/or ill-effects to the unborn child. Latisha promised Luke that she would give up smoking for the duration of the pregnancy, but that she would continue to drink regardless of the circumstances.

As the semester progressed, Luke continued the sessions with Latisha when she attended school. On many of those days, Latisha would spend time in detention for violation of some school policy, frequently having to do with being out of school dress code. Regardless of her in-school status for the day, Luke would find time for discussions and often offered assistance with class or homework assignments. During one week when Latisha had been absent from school, Luke was informed that her mother had committed suicide. Although it had been many years since Latisha had seen her mother, the loss appeared to be devastating. Shortly thereafter, Luke discussed with Latisha his ultimate goal of keeping her in school. Latisha simply responded with a laugh and said, "That's not going to happen." She went on to say, "I'm not going to waste the next three years of my life in school."

Latisha continued to have frequent clashes with the principal because of her absences, defiance, and violations of school policies. The principal agreed to meet with Luke and Latisha to discuss her problems, why she refused to work in school, and her future goals. At one point, Luke surmised that, "the staff here is either afraid of her outbursts and is too lenient on her, or they try to break her and are overly tough on her." They all agreed that regardless of the programs and policies at school, nothing seemed to work well for Latisha.

Luke mentioned to the principal that he and Latisha had talked about an alternative education program called "Life Skills." In this program, the students are only required to attend school for 4 hours per day, and some of the credits can be completed online. Latisha suggested that she might be willing to work harder and would probably be much happier there. During a follow-up conversation with the principal, Luke asked that if Latisha could not be enrolled in the alternative education program, if a special school day schedule of that nature be generated for her. Without making any promises, the principal agreed to discuss the ideas with Latisha's father.

After two more weeks of truancy, Latisha's father withdrew her from school and prepared to enroll her into the alternative education program. One morning, Latisha's sister delivered a handwritten note from her to Luke:

Hey Mr. Luke,

Great news, well for me. I'm not going to be going to this school no more.

I'm going to Life Skills though. But wow. I'm going to miss you a lot dude.

But anyways, the baby is doing great. I went to the doctor's. I'm almost two

months. He/she is doing awesome. Her/his health is fine. Oh, one more thing,

thank you for being there for me and being a true friend. I will never forget you. 
Latisha

PS. Email me. I don't care what the principal says about it.

That was the last time Luke heard from Latisha. School policy forbids teachers from interacting with students other than related to homework or legitimate school business. However, Luke did return a note telling Latisha why he would not be able to communicate with her, but that she had been an important part of his days at school and he wished the best for the baby and her fresh start at a new school.

\subsection{Sarah Attempts to Rescue Deeana}

Deeana is a 19 year old girl whose parents divorced when she was 9 years old. She has two brothers, two sisters, and has only seen her father once in the last 10 years, although her mother has since remarried. From kindergarten through $4^{\text {th }}$ grade, Deeana repeated $1^{\text {st }}$ grade, attended three different elementary schools, and another three schools by the time she was in the $8^{\text {th }}$ grade. While in the $8^{\text {th }}$ grade, Deeana was expelled from school for being involved in four fights. Later that year, Deeana was enrolled in an alternative education program.

Deeana gave birth to a baby girl when she was in the $10^{\text {th }}$ grade at 17 years old, and shortly thereafter was asked to leave home because of conflicts with her mother. Since then, she has spent much of her time moving from place to place, and living with friends or other acquaintances to provide shelter for both herself and the baby. Over the past three years, Deeana has only sporadically attended school, including dropping out for one complete year while she cared for her child.

Sarah teaches in the alternative education program that Deeana now attends, however she met Deeana 7 years earlier at a summer camp where she was a counselor. Even though Sarah learned a great deal about Deeana's life that summer, neither expected their paths would cross again years later. I asked Sarah why she chose Deeana for her rescue attempt, and learned that Sarah was interested because she understood many of the problems that confronted Deeana. One important reason was that Sarah had also given birth to a daughter at a young age, although she was married at the time.

Over the semester that Sarah attempted this rescue, she applied a five-pronged strategy of being teacher, friend, confidant, counselor, and social worker for Deeana. During those months, Sarah found Deeana information and drove her to appointments regarding social services that might be available for her and the baby. Some of those services included temporarily receiving food stamps, WIC benefits, and day care vouchers for the child. Since Deeana lived a substantial distance from school, getting there regularly and on time was sometimes problematic or at least served as an excuse for her not to attend. Deeana needed to maintain the positive habits and interests in school that had begun to develop, so Sarah began to research information on housing closer to the school. Although final housing details had not been worked out, Sarah identified a possible residence that was adjacent to the school grounds. Living in such proximity to the school would eliminate most reasons for absence other than illness of Deeana or the child.

Like other graduate students who opted to participate in the Search and Rescue initiative, Sarah maintained an extensive journal detailing her experiences. However, Sarah became so optimistic about Deeana's new determination to graduate; she invited me to the school to meet Deeana. During the visit I interviewed both Deeana and Sarah about this experience in an attempt to better understand their relationship dynamics and the strategies that Sarah had employed. A highlight of the interview was learning that Deeana had established goals of not only to graduate, but also to attend Cleveland State University someday.

After the interview and Deeana had gone home, I shared some information with Sarah on potential scholarships at Cleveland State University that are specifically designed for impoverished first generation urban college students. Although Deeana would most likely need to spend some time in community college remediation courses before applying to the university, Sarah began to maintain a file of potential funding resources for her. Two weeks later, Sarah and I invited Deeana to attend our class as a special guest speaker on the topic of Rescuing Dropouts and High Risk Students. Her pride at being asked to speak to college students about her life was palpable.

\subsection{Stephanie Attempts to Rescue Terrance}

Terrance is a 23 year old young man who dropped out of school during his senior year. His specific reasons for leaving are still unclear, but generally he talked about his growing sense of frustrations in life as the primary cause. Terrance currently works minimum wage, or otherwise low paying jobs when can find them. Although he is beyond the age to legally re-enroll in public school, Stephanie has known him and his family for some time and was 
committed to attempting his rescue Stephanie established contact with Terrance through his sister, and then began phone communications regarding his high school completion.

After several days of agreeing to meet with Stephanie and missing appointments, they finally sat down to discuss why he left school, how many classes/credits were needed in order to graduate, and what could she do to convince him to return to school. On a subsequent day, Stephanie picked up Terrance at his home and they went to his former high school to review his transcripts. Terrance had informed Stephanie that he had already passed the Ohio Graduation Test (OGT) and was only lacking 2 classes needed for graduation.

Although Stephanie was aware that Terrance was beyond the legal age of public school education, she made phone calls to inquire from the central administration to see if they were in a position to help him to complete high school at this point. The answer was a simple "no" since the district was not obligated help a student of his age. Although somewhat discouraged, Stephanie began to pursue other avenues that would help Terrance obtain his high school diploma.

After several days of online research, Stephanie found an out-of-state nationally accredited high school program that would accept Terrance's accumulated credits, provide the additionally need classes, and have him graduate from their program. Moreover, all of his work could be completed online. Of course all of this would be contingent upon a review of his official transcripts and payment of program fees. To complete Stephanie's inquiry, the high school provided a list of colleges, universities, and technical schools throughout the country that have accepted their graduates.

As the days went on, Stephanie continued communications with Terrance and they discussed the high school program cost of $\$ 675.00$. In his current job, Terrance was making $\$ 50.00$ per day. Later Terrance called Stephanie to say that he wanted to begin the program, and although $\$ 675.00$ was a lot of money, he would be willing to get an additional job to pay the tuition.

A couple weeks later without hearing from Terrance, Stephanie sent a text to make sure he was still interested. His return text said, "I ain't paying for no diploma" and "I won't spend $\$ 700.00$ on a piece of paper." Disappointed but not despairing, Stephanie asked if Terrance would be willing to pursue a GED, to which he agreed. Over the next few days, Stephanie located four area GED testing centers where he could begin practice sessions. This information was given to Terrance, and Stephanie made frequent phone calls to see if he had followed up. The early responses were that he had not taken any action, but he was still interested in pursuing the GED.

Stephanie continued to encourage Terrance, and helped him to map out a plan of what he wanted to accomplish over the next 6 months, one year, and two years respectively. Ongoing texts from Stephanie informed Terrance that he would not "get rid" of her until he had taken positive steps to pursue his education. Finally, Terrance informed Stephanie that he had taken the practice math test, but failed by 20 points. Stephanie continued her attempts to rescue Terrance.

\section{Summary and Conclusions}

It will still be some time, and much more data will need to be collected before the Search and Rescue initiative, or this type of university student engagement can be deemed successful or not. Ultimately, our goal is for the high school students to either return to school, or to remain there until graduation. And, ultimately these students may, but only with the passage of time will we know for sure. Our only certainty is the knowledge that dropping out of school is not just an event, but is more importantly, a long term process. At this point however, we can begin to build upon what we have learned so far from these experiences.

The four graduate students who attempted Search and Rescue are now encouraged to think about what they have learned from this experience, and how that can be applied to improving urban schools. As that semester closed and we summarized our thoughts, many important questions began to emerge. Do urban school districts need to rethink their philosophies and rewrite their mission statements? Can the current concepts and paradigms of what school is remain in place, or do we need a fresh and new design for urban students. What policies, programs, and practices need to be addressed, and in what order? Are there specific teacher characteristics, knowledge bases, qualities, skills, and abilities that work best for urban students? Is there a course of action that will empower urban students to assume greater responsibility for their own learning and commitment to graduation?

Socially and economically speaking, too many urban students bring difficulties with them to school everyday that deny them an opportunity to become engaged learners. For those troubled students, school must become more than a just place where information is disseminated and they are prepared to take competency examinations. Regardless of national standards, end of grade testing, teacher union agreements, and technologically driven schools, when students 
feel hopeless and helpless they fail to see the point of learning and demonstrating their ability to achieve academically.

Studies by Burrus and Roberts (2012) suggests that dropouts and high risk students have usually been on their trajectory for a number of years. Therefore keeping or re-connecting them to school is of low statistical probability. This low probability of success however magnifies the need to increase the number of attempts. Attempting to rescue only one student will most likely result in eventual failure. However, attempting to rescue ten students increases the probably that at least one will return and succeed in school. Regardless of one's perspectives on the "return on this investment", both mathematically and logically speaking, some success is better than no success.

In every case, my graduate students talked about the high levels of intelligence these rescuees apparently possessed. None of rescuees failed because of an inability to learn, but rather, because of a perfect confluence of negative life circumstances, their own poor decision making, and educational institutions are not designed to respond to students with their particular needs. All of my graduate students began to envision leading schools that can best serve the students that do attend, not the students they wish were in attendance.

As for me, regardless of which course I teach, exchanging a standard research paper for an attempt to search for and rescue a dropout or high risk student will always be an option. I believe that in time, my students and I will be able to develop a defined Search and Rescue program with specific techniques and strategies that increase our odds of success. Furthermore, this endeavor pushes me to rethink what is really important for new educational leaders to learn in graduate school. When I can help to develop school leaders that solve long term problems in urban schools, then I will know that I have made a real difference.

\section{References}

Burrus, J., \& R.D. Roberts. (2012). Dropping Out of High School: Prevalence, Risk Factors, and Remediation Strategies. ETS. R\&D Connections. No. 18. February 2012.

Center for Urban Education. (2014). Preliminary Results: Cleveland Metropolitan School District Performance in the First Year of the Cleveland Plan. Cleveland State University. Retrieved from clevelandmetroschools.org/cms/lib05/OH1915844

Cleveland Metropolitan School District. (2017). CMSD Official Website. Retrieved from www.clevelandmetroschools.org/domain/24

Conchas, G. (2006). The Color of Success: Race and High Achieving Urban Youth. Teachers College Press, NY. pp. 7-12.

Doll, J.J, Z. Eslami, \& L. Walters. (2013). Understanding Why Students Drop Out of High School, According to Their Own Reports: Are They Pushed or Pulled, or Do They Fall Out? A Comparative Analysis of Seven Nationally Representative Studies. Sage Open. October-December. pp. 1-15. Retrieved from sgo.sagepub.com

Hampton, F. M. (2013). Search and Rescue. Urban Advocate, Winter, 14-15. 